\title{
Hypertension after coarctation repair-a systematic review
}

\author{
Joseph Panzer ${ }^{1}$, Thierry Bové ${ }^{2}$, Kristof Vandekerckhove ${ }^{1}$, Daniël De Wolf ${ }^{1}$ \\ ${ }^{1}$ Departement Kindercardiologie, Universitair Ziekenhuis Gent (Pediatric Cardiology Department, University Hospital Ghent), Ghent, Belgium; \\ ${ }^{2}$ Departement Hartchirurgie, Universitair Ziekenhuis Gent (Cardiac Surgery, University Hospital Ghent), Ghent, Belgium \\ Contributions: (I) Conception and design: J Panzer, D De Wolf; (II) Administrative support: J Panzer; (III) Provision of study materials or patients: \\ J Panzer, T Bové, K Vandekerckhove, D De Wolf; (IV) Collection and assembly of data: J Panzer; (V) Data analysis and interpretation: J Panzer, T \\ Bové, D De Wolf; (VI) Manuscript writing: All authors; (VII) Final approval of manuscript: All authors. \\ Correspondence to: Dr. Joseph Panzer, MBChB, FCPaed (SA), PhD. UZ Gent 3K12D, Corneel Heymanslaan 10, 9000 Gent, Belgium. \\ Email: Joseph.Panzer@UZGent.be.
}

\begin{abstract}
Background: Coarctation of the Aorta $(\mathrm{CoA})$ leads to increased morbidity and mortality later in life despite early surgical or percutaneous treatment. Many long-term complications are related to hypertension (HT) which is a common finding late after coarctation repair.

Methods: A systematic Review was performed including articles published between February 2012 to December 2020. Systematic searches were conducted on PubMed and the Cochrane Controlled Trials Register to look for studies on HT after aortic CoA-repair. PRISMA guidelines were used.

Results: In this systematic review on HT after CoA Repair the mean prevalence of HT was $47.3 \%(20$ $70 \%$ ). A progressive character was of the HT was found, furthermore if only studies are included with $24 \mathrm{~h}$ blood pressure (BP) recording in addition to standard BP measurements, the incidence of HT rose to $57.8 \%$. Discussion: Most clinical studies look at complications, mortality rate and residual pressure gradient rather than correlating hemodynamic indices with long-term outcome. Although HT is commonly based in measurement of peripheral BP, it has been shown that peripheral BP in CoA patients has a poor correlation with central aortic pressure. Central aortic hemodynamics are significantly altered in patients with repaired CoA, which can now adequately be investigated non-invasively. At the present time there are no studies linking long-term outcome with abnormal central hemodynamics.
\end{abstract}

Keywords: Coarctation of the aorta; hypertension; long-term outcome

Submitted Aug 31, 2021. Accepted for publication Jan 18, 2022.

doi: $10.21037 /$ tp-21-418

View this article at: https://dx.doi.org/10.21037/tp-21-418

\section{Introduction}

Coarctation of the Aorta (CoA) comprises approximately $5-8 \%$ of all structural congenital cardiac lesions. It occurs three times more commonly in males than females. CoA still leads to increased morbidity and mortality later in life despite early surgical or percutaneous treatment. Many long-term complications are related to hypertension (HT) which is a common finding late after coarctation repair.

Improved treatment and surveillance have shifted the emphasis from short-term to long-term outcome (1). Since the last systematic review on HT after CoA published in 2013 by Canniffe et al. (1), important new evidence has emerged on this topic. We therefore revisited a systematic review on $\mathrm{HT}$ after CoA Repair based on findings from 2012 to 2020, with additional focus on pathophysiology. The role of specific hemodynamic indicators of long-term outcome is currently not well understood. We touch on this subject with a brief discussion on ways of assessing central hemodynamics non-invasively. The objective of the systemic review was therefore to establish what has changed since the last systematic review on the topic and to assess whether novel ways of measuring central aortic hemodynamics have been incorporated into studies documenting $\mathrm{HT}$ after $\mathrm{CoA}$ repair.

The holy grail would be to identify preliminary signals 
of potentially harmful pathophysiologic changes, to find treatments that prevent the cascade ending towards established HT. In this way long-term complications related to HT in CoA patients might be anticipated.

We present the following article in accordance with the PRISMA reporting checklist (available at https:// tp.amegroups.com/article/view/10.21037/tp-21-418/rc).

\section{Methods}

A systematic review on the subject of $\mathrm{HT}$ after CoA-repair was performed, with emphasis on articles published in the English language from February 2012 until December 2020. PRISMA guidelines (preferred reporting items for systematic reviews and meta-analysis) were used. Systematic searches were conducted on PubMed and the Cochrane Controlled Trials Register to look for studies on HT after aortic CoA-repair. No restrictions were applied to the status of publication other than the above-mentioned elements. Search Terms were HT, blood-pressure, coarctation repair, coarctation surgery, percutaneous treatment of coarctation, coarctation stenting, age-at-repair, and pathophysiology.

\section{Inclusion and exclusion criteria}

The novel data of this review was compared to these of the systematic review retrieved from 1987 to 2012 (1), based on the use of identical inclusion criteria. Studies were only included when blood pressure (BP) was an outcome measure after coarctation repair. CoA-repair could be either surgically or via catheter-based interventions. Studies also needed to be randomized controlled trials or case-controlled or cross-sectional studies yielding at least 35 patients. Observational studies were included if the study population comprised more than 120 study subjects, with more than 20 years follow-up. The paper of Meijs et al. (2) was excluded for comparison as this meta-analysis investigated the effect of stent therapy on BP changes in the short and medium term, rather than the incidence and prevalence of HT after treatment in the long term.

A PubMed search for articles on CoA initially led to 12,405 articles (Figure 1). Limiting the search to articles published since February 2012, retained 5,905 articles. By excluding duplicates, case reports and systematic reviews the total was brought to 1,913 articles. Of these, abstracts were read to eliminate inappropriate studies. This reduced the total to 358 articles requiring the reading of the full text to ascertain whether the inclusion criteria were fulfilled. Of the 358 articles, 352 were obtained via institutional online access. The remaining full texts were requested via our library, but only 4 published in English were used. After consulting the full content of these 356 articles, only 17 fulfilled the inclusion criteria as set out above (3-19) (Table 1).

The Cochrane Controlled Trials Register was searched for trials reporting on CoA, using $\mathrm{BP}$ as an outcome measure. One hundred seventeen trials were initially identified but only one article had data on long-term CoA outcome (20). The paper of Pádua et al. reported on the efficacy of surgery versus stenting as best treatment of CoA. As HT was not a specific outcome measure, this publication was not included (20).

\section{Data extraction}

One single reviewer extracted all data independently. The acquired information considered BP, HT, age-at-repair, type of repair, duration of follow-up, control group data, vascular measurements, aortic arch geometry, journal, year of publication and first author.

\section{Results}

\section{Standardized definitions}

All studies used as definition for HT a value of $\geq 140 / 90 \mathrm{mmHg}$ or $>$ the $95^{\text {th }}$ percentile in children. In the previous review by Canniffe (1), the definition of HT was not standardized across articles yet.

$24 \mathrm{~h} \mathrm{BP}$ was measured in some studies but there was no standardization of the type of BP devices. Significant differences have been shown when using two different $24 \mathrm{~h}$ BP devices (21).

Medication for HT confounded the results. Some patients were identified as having $\mathrm{HT}$ if they were taking medication for HT, even with normal BP measurements, for example by Bambul Heck et al. (4). Furthermore, it is possible that some antihypertensive medications were started for an indication other than HT, with insufficient data in the studies to test this hypothesis. Mery et al. (15) noted that the usage of cardiac medications for other cardiac conditions might have influenced BP.

BP phenotypes, as outlined in the 2016 European Society of Hypertension guidelines (22), were not routinely categorized. Sendzikaite et al. (17) did find that isolated 


\section{Identification of studies via databases and registers}

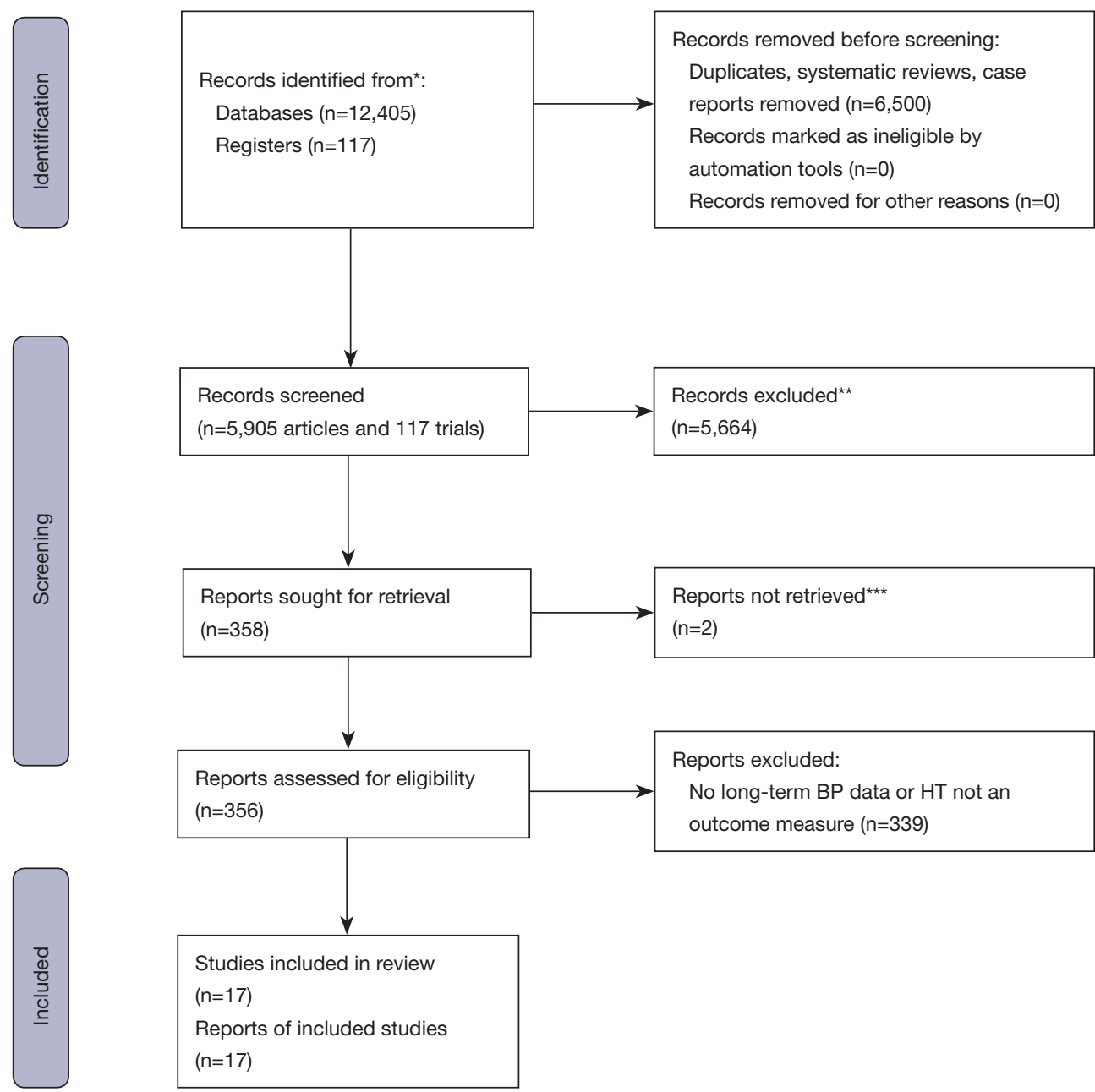

Figure 1 Initial screening. * , PubMed, Cochrane Controlled Trials Register; ${ }^{* *}$, records were excluded by a human not with any automation tools, except limiting by year of publication; no Controlled Trial had long-term BP data and/or included HT as an outcome measure; therefore all 117 trials were excluded; ***, 2 reports were not in English and were excluded. For more information, visit: http://www.prismastatement.org/. BP, blood pressure; HT, hypertension.

systolic HT was the dominant phenotype in CoA patients.

The definition of re-CoA used was an invasive gradient of $20 \mathrm{mmHg}$, however this gradient was estimated in various ways. In some studies, re-CoA was diagnosed by echocardiography (15), in others via magnetic resonance imaging (MRI) $(6,9,11)$ or clinically measuring a noninvasive BP gradient (16).

The definition of exercise induced HT was systolic blood pressure (SBP) $>200 \mathrm{mmHg}$, however Luitingh et al. identified a cut-off of $190 \mathrm{mmHg}$ as a more suitable value to identify those with HT in children (13).

\section{Prevalence of HT in $\mathrm{CoA}$}

The mean prevalence of HT in this systematic review was $47.3 \%$ (range, $20-70 \%$ ). However, the prevalence was as low as $7 \%$ in a specific cohort (12). In a previous review Canniffe et al. found a prevalence of 32,5\% (range, 25-68\%) (1).

There is a progressive character to HT after CoA repair. In a study by Bambul Heck et al. (4), a group of 273 patients were studied previously (COALA study) and reassessed 14 years later. All patients had ambulatory $24 \mathrm{~h} \mathrm{BP}$ measurements. In this study, $23 \%$ of patients were found to 
Table 1 Articles meeting inclusion criteria

\begin{tabular}{|c|c|c|c|c|c|c|c|c|c|c|}
\hline Author & Group & $\begin{array}{c}\text { Standarized } \\
\text { def. HT }\end{array}$ & $\begin{array}{l}\text { Follow-up } \\
\text { (in years) }\end{array}$ & $\begin{array}{l}\text { Age at } \\
\text { surgery }\end{array}$ & $24 \mathrm{~h} \mathrm{BP}$ & $\begin{array}{c}\text { Exercise } \\
\text { test }\end{array}$ & $\begin{array}{c}\text { Re-CoA or } \\
\text { HAA data (\%) }\end{array}$ & HT (\%) & $\begin{array}{l}\text { Surgery (\%) vs. } \\
\text { percutaneous }\end{array}$ & BAV (\%) \\
\hline Bambul Heck (4) & 273 & Yes & $31.4(14.1-39.9)$ & $9.7(0-56)$ & Yes & Yes & - & 70 & 100 & 48 \\
\hline Chen (6) & 247 & Yes & 5.9 & $\begin{array}{c}\text { S: } 6(0-55) \\
\text { I: } 25(0.5-64)\end{array}$ & No & No & $\begin{array}{c}31 \text { re-CoA, } \\
25.9 \mathrm{HAA}\end{array}$ & 69.6 & 81 & 56 \\
\hline Choudhary (7) & 151 & Yes & $26 \pm 13$ & $5(0-10)$ & No & No & 31 re-CoA & 44 & Mixed & 66 \\
\hline Dijkema (8) & 206 & Yes & 12.5 & $0.1(0-17)$ & No & No & $21 \mathrm{HAA}$ & 20 & 86 & 39 \\
\hline Egbe (9) & 546 & Yes & Age $33 \pm 9$ & - & No & Yes & - & 60 & 87 & 57 \\
\hline Giordano (10) & 148 & Yes & $13.3 \pm 4.5$ & $0.4(0-11.8)$ & Yes & Yes & - & 44 & 100 & - \\
\hline Luitingh (13) & 41 & Yes & $13 \pm 3$ & $0.03(0.02-0.1)$ & Yes & Yes & $32 \mathrm{HAA}$ & $\begin{array}{l}39 \text { (12 on } \\
\text { exercise } \\
\text { test) }\end{array}$ & 100 & 61 \\
\hline Martins (14) & 75 & Yes & $9-12^{\star \star}$ & $\begin{array}{c}\text { S } 6 \text { [1-26], } \\
\text { BD } 5 \text { [1-17], } \\
\text { ST } 15 \text { [7-26] }\end{array}$ & Yes & Yes & - & $\begin{array}{c}30 \mathrm{~S}, 39 \\
\mathrm{BD}, 45 \mathrm{ST}\end{array}$ & Mixed & $\begin{array}{l}79 \mathrm{~S} \\
45 \mathrm{~B}\end{array}$ \\
\hline Mery (15) & 343 & Yes & $12(0.5-19)$ & $0.1(0-0.75)$ & No & No & 33 HAA & 33 & 100 & - \\
\hline Rinnström (16) & 653 & Yes & $27.4 \pm 12.8$ & $9.5 \pm 11$ & No & No & 49 re-CoA & 52.7 & 94 & - \\
\hline
\end{tabular}

*, including self-reported HT; ${ }^{* *}$, data divers in cohorts. HT, hypertension; BP, blood pressure; CoA, coarctation of the Aorta; HAA, hypoplastic aortic arch; BAV, bicuspid aortic valve; S, surgery; B, balloon dilatation; I, interventional treatment; BD, balloon dilatation; ST, stent.

have HT with $25 \%$ taking anti-hypertensive drugs initially. 14 years later $53 \%$ of the same patient group were found to have HT with nearly half receiving antihypertensive medication. Furthermore, the studies with the longest follow-up found the highest incidence of HT $(5,7,9,16,17)$.

\section{Influence of re-CoA}

HT developing in CoA patients without documented residual narrowing was not viewed separately from those with residual obstruction. A limitation in extracting BP data from these studies is that in most cases the BP data does not differentiate between those with re-CoA and those without. Some studies report on the incidence of re-CoA or hypoplastic arches, but failed to separate the BP data. However, Choudhary et al. (7) and Chen et al. (6) found no clear correlation in the prevalence of HT in those with and without re-stenosis.

\section{4 b BP}

$24 \mathrm{~h} \mathrm{BP}$ was performed in 6 studies $(3,4,10,13,14,17)$. It is interesting to note that Luitingh et al. compared the incidence of HT in patients at rest, after $24 \mathrm{~h} \mathrm{BP}$ recording 
and during exercise (13). They found that of the 41 patients, $5 \%$ showed resting HT while $39 \%$ had HT on $24 \mathrm{~h} \mathrm{BP}$ measurements. As expected, a higher prevalence of HT was found if $24 \mathrm{~h} \mathrm{BP}$ registration was performed but no additional cases were identified by exercise testing. If only studies are included recording $24 \mathrm{~h} \mathrm{BP}$ recording in addition to standard BP measurements, the incidence of HT rises to $57.8 \%$, which is $10 \%$ higher compared to only standard BP measurement.

\section{Exercise testing}

Exercise Tests were performed in 6 studies $(3,4,9,10,13,14)$. Luitingh $e t a l$. found an overall reduced exercise endurance in CoA patients compared to the control group (13). The mean SBP at peak exercise was higher in the coarctation population $(164 \pm 26$ vs. $148 \pm 19 \mathrm{mmHg}, \mathrm{P}=0.003)$. Five of the $41(12 \%)$ coarctation patients had a peak exercise SBP $>200 \mathrm{mmHg}$ and were therefore considered to have exercise-induced HT, although they went on to propose a cut-off value of $>190 \mathrm{mmHg}$ in children. Róg et al. found lower values of peak $\mathrm{VO}_{2} / \mathrm{kg}$, heart rate peak and \% max heart rate (HR) in CoA patients during exercise testing compared to controls (3). They postulated that most of the findings were due to chronotropic incompetence.

\section{Other factors influencing $H T$}

Age at repair was the main determinant of HT in various studies, with older age at repair being associated with an increased incidence of $\mathrm{HT}(5,7,12,17)$, but not in the studies of Bambul Heck et al. (4) and Rinnström et al. (16).

The type of repair was also found to be important. Giordano et al. (10), compared a group of patients with isolated $\mathrm{CoA}$ (148 patients) with patients having CoA as part of a complex congenital heart disease (CHD) (87 patients). Although patients with isolated CoA were significantly younger, they had a markedly higher incidence of HT (44\% vs. 24\%). They postulated that in the complex CHD group, the incidence of HT was lower because the aortic repair was more effective than in those with isolated CoA, possibly due to less residual aortic arch hypoplasia through aortic arch enlargement with a pulmonary homograft patch. Martins et al. failed to demonstrate that the type of repair was predictive for vascular function differences and HT when comparing surgery $v s$. balloon dilatation (BD) $v s$. stents (14).

Patients treated in different eras were compared by
Dijkema et al. (8). They now favor enlarging the transverse arch, as it has been shown that catch-up growth of arch hypoplasia after end-to-end anastomosis does not always occur (23).

Obesity was studied as a separate outcome measurement by Smith-Parrish et al. in a cross-sectional study involving coarctation patients (18). They found an alarming and increasing prevalence of obesity of $26 \%$ at the age of 10 years, and $63 \%$ at the age of 20 years. There was good correlation between obesity and HT in their study. Rinnström et al. (16) also revealed an association between HT and obesity.

The increased risk of a cerebro-vascular accident (CVA) after coarctation repair was found to be three-fold, with HT the single best predictor of CVA [Wu et al. (19)].

\section{Arterial bemodynamic factors}

Pulse wave velocity (PWV) is commonly used to assess vascular hemodynamics in the clinical setting. It mainly assesses aortic stiffness. Luitingh et al. found a significantly higher PWV in CoA patients compared to controls (13). However, carotid artery distensibility and arterial stiffness index were similar in both groups. Carotid intima media thickness (IMT) was also measured and found to be significantly raised in CoA patients even without HT (3). In a multicenter, cross-sectional, observational comparison of vascular function in CoA patients, Martins et al. (14) found that major vascular outcomes (prevalence of HT, global aortic stiffness, central BP and endothelial function) were similar in CoA patients treated with BD, stenting or surgery. Through segmental assessment of PWV and distensibility measures by cardiac magnetic resonance (CMR) they revealed that proximal aortic stiffness was lowest in the $\mathrm{BD}$ patients and highest in the stenting group.

\section{Cardiac bemodynamic factors}

Selected studies measured left ventricle (LV) hemodynamic factors, usually systolic and sometimes diastolic LV function with echocardiography $(4,9,13,17)$. Martins et al. looked at LV mass, usually derived from echo-measurements (14). There was an important prevalence of left ventricular hypertrophy (LVH) in the absence of HT. Sendzikaite et al. found a similar proportion of LVH in normotensive (31\%) and hypertensive patients (33\%) with repaired CoA (17). Chen et al. measured LV function and mass 
with CMR (6). They found a strong relation between an increased LV mass and the risk of hospitalization. Egbe et al. looked at LV diastolic dysfunction and found that the aortic isthmus ratio (ratio of the aortic isthmus diameter to the descending aorta diameter at the level of the diaphragm $\leq 0.5$ ) had a strong correlation with diastolic dysfunction and exertional symptoms (9).

\section{Discussion}

Despite successful treatment of aortic CoA, long-term morbidity and mortality remains higher in this patient population compared to controls. Frequent problems found in the long-term follow-up of these patients are early onset of cardiovascular diseases like myocardial infarction, cardiac failure, stroke, and even sudden death, often in the setting of arterial HT. The incidence of HT found in this systematic review, is high at $47.3 \%$.

Various factors influence the development of HT. Cohen and colleagues already reported in 1989 that the most important determinant of long-term survival and HT in CoA patients was the age of patients at the time of the initial repair (24). This finding was confirmed in many studies $(5,7,12,17)$, except for a few recent studies $(4,16)$. Rinnström et al. followed up patients during 3 decades after $\mathrm{CoA}$ repair and found that the age at intervention was less important than the age at follow-up, postulating that the beneficial effect of early repair might eventually wear off as patients age (16).

In general, HT is based on measurement of the peripheral BP, being the simplest measure of afterload. However, peripheral BP can deviate from central aortic pressure in patients with repaired CoA, limiting thereby its value in assessing properly the vascular and cardiac hemodynamics after CoA repair (25).

Already in 1971, O'Rourke and Cartmill suggested that morbidity in CoA patients was related to abnormal hemodynamics and vascular biomechanics (26). Recent developments in experimental and computational methods seem to support this theory (27). Factors contributing to an increased LV afterload are (I) a residual narrowing leading to additional resistance and (II) a less distensible aorta interfering with the buffer function of the aorta. The proximal aortic wall in patients with repaired CoA has been shown to have different histology, containing more collagen, less elastin fibers, and less smooth muscle cells.
Compliance and distensibility of the aorta are therefore impaired in comparison with healthy individuals. Schäfer et al. found increased stiffness of the ascending aorta on MRI after CoA Repair with higher central aortic BP (28).

Central aortic pressure can be predicted by using the descending aortic distension waveform as a substitute for the pressure waveform and by scaling it to the measured brachial pressure in a fluid-structure interaction (FSI) (29). Quail et al. demonstrated the ability to assess central aortic SBP (c-SBP) non-invasively using a combination of phase-contrast magnetic resonance and oscillometric brachial artery BP (30). They also showed that it was possible to use the same high temporal-resolution phase-contrast magnetic resonance data to perform noninvasive wave intensity analysis (WIA) in patients with repaired CoA. Using this technique, the central aortic pressure was significantly higher in patients with repaired CoA compared to controls (30). Patients with repaired CoA had reduced total arterial compliance, increased pulse wave velocity, and larger backward compression waves, resulting in a higher left ventricular mass (LVM) index. The magnitude of the backward compression waves was independently associated with variation in LVM (31). Egbe et al. also showed that SBP may underestimate LV afterload after CoA repair since CoA patients have a higher arterial afterload compared with controls, even with similar $\operatorname{SBP}(25,32)$.

Recently abnormal diastolic LV function on echocardiography was shown to be related to proximal aortic elasticity $(33,34)$. The authors postulated that in children who had a successful CoA repair very early in life, persistently elevated aortic stiffness may lead to diastolic impairment. We also found decreased diastolic $\mathrm{LV}$ function in children with repaired CoA, despite early repair and absence of residual stenosis (35). It has long been proposed that (early) arterial reflection waves generated by scar tissue at the repair site or by a stent leads to a new pressure wave reflection, generating LVH, considered as an adaptive response to maintain wall stress. Histologically cardiomyocyte size and density increase and fibrosis ensues. This leads to changes in the viscoelastic properties and results in increased LV filling pressures. This is clinically translated in the development of LVH, regardless of HT in CoA patients (17).

We showed in an experimental animal study that despite adequate relief of aortic coarctation, the Ventricular-Arterial 
(VA) hemodynamic relationship is compromised, depending on the sequelae of aortic treatment varying from a short residual stenosis to long non-stenotic aortic stiffening as by aortic stenting. Moreover, the impaired VA coupling is enhanced after inotropic stimulation, suggesting that the ventricular adaptation to the altered vascular dynamics may be underestimated, becoming unmasked during exercise. Although the therapeutic approach aims for complete elimination of the transaortic pressure gradient, the impact on other components of aortic hemodynamics or $\mathrm{LV}$ function often remains unsolved (36).

The role of specific hemodynamic indicators of longterm outcome is currently not well understood and unfortunately, none of the included studies assessed aortic and ventricular hemodynamics comprehensively by using currently available techniques, like the MRIbased assessment demonstrated by Quail et al. outlined previously (30). It would have been interesting to correlate these comprehensive parameters of central aortic hemodynamics with long-term outcome, but so far, such studies are lacking.

Most of the clinical studies on CoA look at complications, mortality rate and residual pressure gradient rather than correlating hemodynamic indices with long-term outcome $(2,5,20,24,37,38)$. In this systematic review, many of the included studies only briefly touch on the underlying vascular mechanisms involved in the pathophysiology of HT (as can be seen in Table 2), with one exception where detailed vascular function was compared in three groups of CoA-repair (14). The relevance of the hemodynamic factors can be divided into arterial- and cardiac components. Various studies tried to assess arterial hemodynamic factors with PWV, carotid IMT, endothelial function, aortic distensibility and, in one study, with central BP (14). Ventricular function was assessed with echocardiographic and occasionally CMR measurements of systolic and diastolic function, degree of $\mathrm{LVH}$ and exercise testing with metabolic measurements.

Aortic arch morphology has been found to contribute to abnormal vascular remodelling various studies, with a gothic arch having the greatest effect, Quail et al. showed recently in an MRI based study that while there are many variations in $3 \mathrm{D}$ aortic shape after coarctation repair, there was only a modest association between variation in aortic radius and pathological wave reflections, but not with $3 \mathrm{D}$ curvature.
This suggests that $3 \mathrm{D}$ shape is not the major determinant of vascular load following coarctation repair, calibre being more important than curvature (31). It is known that Aortic size mismatch between the ascending and descending aorta (DAAo/DDAo) can be predictive for exercise intolerance in repaired coarctation (39).

Finally, we must not forget that factors leading to HT unrelated to the heart or the aorta itself have also been identified. As an interesting example, Rodrigues et al. showed that vertebral artery hypoplasia (VAH) with an incomplete posterior circle of Willis (ipCoW) led to an increase in cerebrovascular resistance before the onset of increased sympathetic nerve activity in borderline hypertensive humans (40). To increase cerebral blood flow, $\mathrm{BP}$ had to rise, leading to the description "the selfish brain". They found that CoA patients were 5.8 times more likely to have VAH + ipCoW than controls, as identified by MRI.

\section{Conclusions}

(I) The prevalence of HT after CoA-repair is substantial and progressive, and higher than previously reported by Canniffe et al. (1).

(II) Routine $24 \mathrm{~h} \mathrm{BP}$ measurement is recommended in the follow-up of patients after CoA repair to identify HT.

(III) LV diastolic dysfunction and LVH are common in patients with repaired CoA, even in the absence of HT, and correlates with worse long-term outcome.

(IV) There is poor correlation between peripheral BP and central aortic BP in CoA patients. Central aortic hemodynamics are significantly altered in patients with repaired CoA, and can now be investigated comprehensively and non-invasively through MRIbased analysis. At the present time there are no studies linking long-term outcome with abnormal central hemodynamics. However, it is expected that abnormal central aortic hemodynamics and pressure should have an even more deleterious effect on the heart and brain than peripherally raised BP. Further studies are needed to elucidate whether it might be beneficial to treat patients with abnormal central aortic hemodynamics with anti-hypertensive medication. 
Table 2 Data acquisition from the included articles to investigate the etiology of HT after CoA-repair

\begin{tabular}{|c|c|c|c|c|c|c|c|}
\hline Author & Group & $\begin{array}{l}\text { Patho-physiology } \\
\text { of HT investigated? }\end{array}$ & $\begin{array}{l}\text { Assessment central } \\
\text { hemodynamics? }\end{array}$ & $\begin{array}{l}\text { Assessment of } \\
\text { arterial factors? }\end{array}$ & $\begin{array}{l}\text { Assessment of } \\
\text { cardiac factors? }\end{array}$ & $\begin{array}{l}\text { Assessment of } \\
\text { 3D aortic arch? }\end{array}$ & $\begin{array}{l}\text { Retrospective data } \\
\text { such as age at } R x \\
\text { and type of } R x\end{array}$ \\
\hline Brown (5) & 819 & No & No & No & No & No & Yes \\
\hline Choudhary (7) & 151 & No & No & No & No & No & Yes \\
\hline Dijkema (8) & 206 & No & No & No & No & No & Yes \\
\hline Egbe (9) & 546 & Yes & No & $\begin{array}{c}\text { Only anatomical } \\
\text { data, CT/MRI }\end{array}$ & $\begin{array}{l}\text { LV diast fx, LV } \\
\text { mass (echo) }\end{array}$ & No & Limited data \\
\hline Lee (11) & 834 & No & No & No & No & No & Yes \\
\hline Lillitos (12) & 87 & No & No & No & No & No & Yes \\
\hline Luitingh (13) & 41 & Yes & $\begin{array}{l}\text { Partially via carotid } \\
\text { echo }\end{array}$ & $\begin{array}{l}\text { Yes, carotid IMT, } \\
\text { stiffness and } \\
\text { distensibility, PWV }\end{array}$ & $\begin{array}{l}\text { LV syst fx, LV } \\
\text { mass (echo) }\end{array}$ & No & Yes \\
\hline Martins (14) & 75 & Yes & $\begin{array}{c}\text { Yes, but not } \\
\text { comprehensively }\end{array}$ & $\begin{array}{l}\text { Aortic stiffness } \\
\text { (applanation } \\
\text { tonometry, MRI, } \\
\text { PWV), endothelial } \\
\text { fx (endo-PAT), } \\
\text { biomarkers } \\
\text { enothelial fx }\end{array}$ & $\begin{array}{c}\text { LV mass, LV syst } \\
\text { fx (MRI) }\end{array}$ & Yes & Limited \\
\hline Rinnström (16) & 653 & Yes with BMI & No & No & No & No & Yes \\
\hline Róg (3) & 58 & Yes & $\begin{array}{l}\text { Partially via carotid } \\
\text { echo }\end{array}$ & $\begin{array}{l}\text { Anatomical data } \\
\text { (echo), carotid IMT }\end{array}$ & $\begin{array}{c}\text { LV mass, LV syst } \\
\text { fx, LV diast fx } \\
\text { (echo) }\end{array}$ & No & Yes \\
\hline Sendzikaite (17) & 90 & Yes also BMI & No & No & LV mass (echo) & No & Yes \\
\hline Smith-Parrish (18) & 160 & Yes with BMI & No & No & No & No & Yes \\
\hline Wu (19) & 2295 & No & No & No & No & No & Yes \\
\hline
\end{tabular}

HT, hypertension; CoA, coarctation of the Aorta; MRI, magnetic resonance imaging; LV, left ventricle; CT, computed tomography; diast, diastolic; echo, transthoracic or transoesophageal; syst, systolic function; IMT, intima media thickness; PWV, pulse wave velocity; PAT, peripheral arterial tone; BMI, brain natriuretic peptide. 


\section{Acknowledgments}

Funding: None.

\section{Footnote}

Reporting Checklist: The authors have completed the PRISMA reporting checklist (available at https:// tp.amegroups.com/article/view/10.21037/tp-21-418/rc).

Conflicts of Interest: All authors have completed the ICMJE uniform disclosure form (available at https://tp.amegroups. com/article/view/10.21037/tp-21-418/coif). The authors have no conflicts of interest to declare.

Ethical Statement: The authors are accountable for all aspects of the work in ensuring that questions related to the accuracy or integrity of any part of the work are appropriately investigated and resolved.

Open Access Statement: This is an Open Access article distributed in accordance with the Creative Commons Attribution-NonCommercial-NoDerivs 4.0 International License (CC BY-NC-ND 4.0), which permits the noncommercial replication and distribution of the article with the strict proviso that no changes or edits are made and the original work is properly cited (including links to both the formal publication through the relevant DOI and the license). See: https://creativecommons.org/licenses/by-nc-nd/4.0/.

\section{References}

1. Canniffe C, Ou P, Walsh K, et al. Hypertension after repair of aortic coarctation--a systematic review. Int J Cardiol 2013;167:2456-61.

2. Meijs TA, Warmerdam EG, Slieker MG, et al. Mediumterm systemic blood pressure after stenting of aortic coarctation: a systematic review and meta-analysis. Heart 2019;105:1464-70.

3. Róg B, Okólska M, Weryński P, et al. Long-term observation of adults after successful repair of aortic coarctation. Postepy Kardiol Interwencyjnej 2019;15:455-64.

4. Bambul Heck P, Pabst von Ohain J, Kaemmerer H, et al. Arterial Hypertension after Coarctation-Repair in Longterm Follow-up (CoAFU): Predictive Value of Clinical Variables. Int J Cardiol 2017;246:42-5.

5. Brown ML, Burkhart HM, Connolly HM, et al. Coarctation of the aorta: lifelong surveillance is mandatory following surgical repair. J Am Coll Cardiol 2013;62:1020-5.

6. Chen SS, Dimopoulos K, Alonso-Gonzalez R, et al. Prevalence and prognostic implication of restenosis or dilatation at the aortic coarctation repair site assessed by cardiovascular MRI in adult patients late after coarctation repair. Int J Cardiol 2014;173:209-15.

7. Choudhary P, Canniffe C, Jackson DJ, et al. Late outcomes in adults with coarctation of the aorta. Heart 2015;101:1190-5.

8. Dijkema EJ, Dik L, Breur JMP, et al. Two decades of aortic coarctation treatment in children; evaluating techniques. Neth Heart J 2021;29:98-104.

9. Egbe AC, Qureshi MY, Connolly HM. Determinants of Left Ventricular Diastolic Function and Exertional Symptoms in Adults With Coarctation of Aorta. Circ Heart Fail 2020;13:e006651.

10. Giordano U, Chinali M, Franceschini A, et al. Impact of complex congenital heart disease on the prevalence of arterial hypertension after aortic coarctation repair. Eur J Cardiothorac Surg 2019;55:559-63.

11. Lee MGY, Babu-Narayan SV, Kempny A, et al. Long-term mortality and cardiovascular burden for adult survivors of coarctation of the aorta. Heart 2019;105:1190-6.

12. Lillitos PJ, Nassar MS, Tibby SM, et al. Is the medical treatment for arterial hypertension after primary aortic coarctation repair related to age at surgery? A retrospective cohort study. Cardiol Young 2017;27:1701-7.

13. Luitingh TL, Lee MGY, Jones B, et al. A Cross-Sectional Study of the Prevalence of Exercise-Induced Hypertension in Childhood Following Repair of Coarctation of the Aorta. Heart Lung Circ 2019;28:792-9.

14. Martins JD, Zachariah J, Selamet Tierney ES, et al. Impact of Treatment Modality on Vascular Function in Coarctation of the Aorta: The LOVE - COARCT Study. J Am Heart Assoc 2019;8:e011536.

15. Mery CM, Guzmán-Pruneda FA, Trost JG Jr, et al. Contemporary Results of Aortic Coarctation Repair Through Left Thoracotomy. Ann Thorac Surg 2015;100:1039-46.

16. Rinnström D, Dellborg M, Thilén U, et al. Hypertension in adults with repaired coarctation of the aorta. Am Heart J 2016;181:10-5.

17. Sendzikaite S, Sudikiene R, Tarutis V, et al. Prevalence of arterial hypertension, hemodynamic phenotypes, and left ventricular hypertrophy in children after coarctation repair: a multicenter cross-sectional study. Pediatr Nephrol 2020;35:2147-55. 
18. Smith-Parrish M, Yu S, Rocchini A. Obesity and elevated blood pressure following repair of coarctation of the aorta. J Pediatr 2014;164:1074-1078.e1.

19. Wu MH, Chen HC, Kao FY, et al. Risk of Systemic Hypertension and Cerebrovascular Accident in Patients With Aortic Coarctation Aged <60 Years (from a National Database Study). Am J Cardiol 2015;116:779-84.

20. Pádua LM, Garcia LC, Rubira CJ, et al. Stent placement versus surgery for coarctation of the thoracic aorta. Cochrane Database Syst Rev 2012;(5):CD008204.

21. Lee MGY, Mynard JP, Luitingh TL, et al. Major DeviceDependence of Measured Hypertensive Status From 24Hour Ambulatory Blood Pressure Monitoring After Aortic Coarctation Repair. Heart Lung Circ 2019;28:1082-9.

22. Lurbe E, Agabiti-Rosei E, Cruickshank JK, et al. 2016 European Society of Hypertension guidelines for the management of high blood pressure in children and adolescents. J Hypertens 2016;34:1887-920.

23. Myers JL, McConnell BA, Waldhausen JA. Coarctation of the aorta in infants: does the aortic arch grow after repair? Ann Thorac Surg 1992;54:869-74; discussion 874-5.

24. Cohen M, Fuster V, Steele PM, et al. Coarctation of the aorta. Long-term follow-up and prediction of outcome after surgical correction. Circulation 1989;80:840-5.

25. Egbe AC, Miranda WR, Connolly HM. Increased prevalence of left ventricular diastolic dysfunction in adults with repaired coarctation of aorta. Int J Cardiol Heart Vasc 2020;28:100530.

26. O'Rourke MF, Cartmill TB. Influence of aortic coarctation on pulsatle hemodynamics in the proximal aorta. Circulation 1971;44:281-92.

27. Ladisa JF Jr, Taylor CA, Feinstein JA. AORTIC COARCTATION: RECENT DEVELOPMENTS IN EXPERIMENTAL AND COMPUTATIONAL METHODS TO ASSESS TREATMENTS FOR THIS SIMPLE CONDITION. Prog Pediatr Cardiol 2010;30:45-9.

28. Schäfer M, Morgan GJ, Mitchell MB, et al. Impact of different coarctation therapies on aortic stiffness: phase-contrast MRI study. Int J Cardiovasc Imaging 2018;34:1459-69.

29. Taelman L, Bols J, Degroote J, et al. Differential impact of local stiffening and narrowing on hemodynamics in repaired aortic coarctation: an FSI study. Med Biol Eng Comput 2016;54:497-510.

30. Quail MA, Short R, Pandya B, et al. Abnormal Wave Reflections and Left Ventricular Hypertrophy Late
After Coarctation of the Aorta Repair. Hypertension 2017;69:501-9.

31. Quail MA, Segers P, Steeden JA, et al. The aorta after coarctation repair - effects of calibre and curvature on arterial haemodynamics. J Cardiovasc Magn Reson 2019;21:22.

32. Egbe AC, Reddy YNV, Obokata M, et al. Doppler-Derived Arterial Load Indices Better Reflect Left Ventricular Afterload Than Systolic Blood Pressure in Coarctation of Aorta. Circ Cardiovasc Imaging 2020;13:e009672.

33. Lombardi KC, Northrup V, McNamara RL, et al. Aortic stiffness and left ventricular diastolic function in children following early repair of aortic coarctation. Am J Cardiol 2013;112:1828-33.

34. Kühn A, Baumgartner D, Baumgartner C, et al. Impaired elastic properties of the ascending aorta persist within the first 3 years after neonatal coarctation repair. Pediatr Cardiol 2009;30:46-51.

35. Panzer J, Dequeker L, Coomans I, et al. Echocardiography during submaximal isometric exercise in children with repaired coarctation of the aorta compared with controls. Open Heart 2019;6:e001075.

36. Panzer J, De Somer F, Segers P, et al. Effect of aortic stiffness versus stenosis on ventriculo-arterial interaction in an experimental model of coarctation repair. Eur J Cardiothorac Surg 2020;58:1206-15.

37. Wu Y, Jin X, Kuang H, et al. Is balloon angioplasty superior to surgery in the treatment of paediatric native coarctation of the aorta: a systematic review and meta-analysis. Interact Cardiovasc Thorac Surg 2019;28:291-300.

38. Cowley CG, Orsmond GS, Feola P, et al. Long-term, randomized comparison of balloon angioplasty and surgery for native coarctation of the aorta in childhood. Circulation 2005;111:3453-6.

39. Mandell JG, Loke YH, Mass PN, et al. Aorta size mismatch predicts decreased exercise capacity in patients with successfully repaired coarctation of the aorta. J Thorac Cardiovasc Surg 2021;162:183-192.e2.

40. Rodrigues JCL, Jaring MFR, Werndle MC, et al. Repaired coarctation of the aorta, persistent arterial hypertension and the selfish brain. J Cardiovasc Magn Reson 2019;21:68.

Cite this article as: Panzer J, Bové T, Vandekerckhove K, De Wolf D. Hypertension after coarctation repair-a systematic review. Transl Pediatr 2022;11(2):270-279. doi: 10.21037/tp-21-418 